THURSDAY, FEBRUARY 26, 1874

\section{THE ROTHAMSTED AGRICULTURAL INVESTIGATIONS}

T $\mathrm{T}$ has become a trite remark, that while both the progress and teaching of Science are fostered in most educated countries by the care of the State, they mainly depend in our own country on the exertions of private individuals; this fact is perhaps, however, more strikingly seen in the case of agriculture than in any other instance. The traveller in Germany will find scattered over the country, some forty Experimental Stations and Agri. cultural Academies, establishments which are devoted to the investigation and teaching of scientific agriculture and are maintained by their respective States. The German farmer has thus the means of becoming acquainted with the true science of his business, and provision is at the same time made for the investigation of the various problems with which his work abounds. In England the state of things is, alas, wholly different. We have just one college-that at Cirencester, devoted to the teaching of scientific agriculture, and one Experimental Station-that at Rothamsted. There is indeed some experimental work done by local Farmers' Clubs, but this is generally only with the object of comparing the effects of the various manures that are in the market, and with no scientific aim or result. Yet England preeminently needs the help of Science to direct economically her vast system of agriculture. The art of agri. culture is here in a higher state of development than on the continent. More capital is here invested in the land; more attention has been paid to tillage, to artificial manures, and to the breeding and feeding of stock. The British farmer succeeds because he is a practical man, and has good common sense, and the enterprising spirit of his race; what might he not do if he thoroughly understood the principles which underlie his art?

If we have but one agricultural station in England we have at least reason to be proud of it. The work done at Mr. Lawes' estate at Rothamsted is not to be equalled by that of any of the foreign stations; indeed, in several departments of investigation it might safely challenge a comparison with their united efforts. This excellence has arisen from the systematic and thorough manner in which the subjects taken up have been treated. We cannot better illustrate this than by referring to the last contribution from Rothamsted, a report by Messrs. Lawes and Gilbert on the growth of barley.*

In one of the experimental fields barley has been grown for twenty years, and the experiment is still progressing. The field is divided into plots of about one-fifth of an acre; some of these have never received any manure during the twenty years ; the others receive some one or more of the food constituents which barley requires. Thus one is manured with phosphates, a second with alkalies, a third with ammonia, a fourth with ammonia and phosphates, a fifth with ammonia, phosphates, and alkalies, \&c. The same manures are always applied each year to the same plot. At harvest the crops are carefully weighed,

* " Report of Experiments on the Growth of Barley for twenty years in succession on the same land," by J. B. Lawes, F.R.S., F.C.S., and J. H. Gilbert, Ph.D., F.R.S., F.C.S.- Fournal of the Royal A gricultural Society, 1873,89 and 275 .

VOL. IX. -No. 226 and are then analysed in the laboratory under the superintendence of Dr. Gilbert, the amount of dry matter, ash and nitrogen being determined. The advantages of this systematic mode of experimenting are very great. Carried on in the same manner for so many years, these experiments answerquestions relating to the exhaustion of soil, to the permanent effect of manures, to the effect of season upon the produce. With the aid of the laboratory investigations they teach us what proportion of the various ingredients supplied in the manure is recovered in the crop, and how the composition of the plant is affected by the various conditions of the soil. In conjunction with analyses of the soil and of the drainage water, we learn what becomes of the manures applied, how deeply they have penetrated into the soil, what is the loss suffered through drainage, \&c. A single field experiment thus thoroughly and patiently carried out touches half the domain of agricultural chemistry, and supplies information of the most solid and valuable kind.

The value of every trustworthy investigation is increased as others are completed which compare with it the work at Rothamsted thus derives an additional value from its extent. During the last thirty years Messrs. Lawes and Gilbert have investigated in the manner described all the principal farm crops, experimenting both on each singly, and also on their behaviour when grown in rotation. As the results are gradually published, and we are able to compare the behaviour of different crops grown on the same soil, with the same manures, and in the same seasons, the special characteristics of each crop become plainly shown by contrast with its fellows, and we gradually learn the part which each is fitted to play in a scientific system of agriculture.

Nitrogenous manures are of primary importance if luxuriant cereal crops are to be raised, the natural supply of combined nitrogen from the atmosphere being very small, and the crops in question having little power for assimilating the forms of nitrogen chiefly present in the soil. Nitrogenous manures are, moreover, as every farmer knows, very expensive, and it is a matter of great importance to employ them in the most economical manner. Messrs. Lawes and Gilbert, knowing the composition of the manure that has gone on to their fields, and the com. position of the crops that have been carted off, can tell exactly what proportion of the nitrogen applied has been assimilated by the plant. They find, on an average of twenty years, that wheat assimilates about 45 per cent. of the nitrogen in a spring dressing of nitrate of sodium, and about 33 per cent. in the case of an autumn dressing of sulphate of ammonium, and only I $4 \frac{1}{2}$ per cent. of the nitrogen supplied by farmyard manure. With barley, the proportion assimilated is rather greater, being 49 per cent. for a spring dressing of ammonium salts. The question as to what becomes of the large proportion of unused nitrogen is clearly of the highest importance. Analyses of the soils, and of the drainage water, throw much light on the subject. The soils of the wheat field have been analysed down to a depth of 27 inches. A considerable part of the missing nitrogen is found to be actually present in the soil, but since it has scarcely any effect on the crops, it is apparently in some state of combination unsuitable for the plant's use. A still larger portion of the nitro- 
gen is, however, not to be found in the soil, but the examination of the drainage waters from the different plots exhibits so large a content of nitrates, that calculation leads to the belief that in the case of ammonium salts and nitrate of sodium the loss of nitrogen chiefly takes place in this manner. Chemists knowing that ammonia is readily absorbed and firmly held by soil, had never anticipated that so considerable a loss might occur by drainage. It plainly appears, however, from these results, that ammonia when applied to the soil is quickly converted into nitric acid, and in heavy rains may be easily washed out. During autumn and winter there is little evaporation from the soil, and no consumption of water by a growing crop ; as soon therefore as the surface soil is saturated most of the subsequent rain-fall will pass into the subsoil, or find its exit through the drains. The authors calculate that if the drainage water contains I part of nitrogen in 100,000, and many of the waters analysed were much richer, there will be a loss of $2 \cdot 26$ ths of nitrogen (equal to about 23 lbs. of guano) for every inch of rain that passes beyond the reach of the roots. It is evident, among other conclusions from these important facts, that ammonia should only be applied to the land in the spring, when the crop is able to make immediate use of it. It may also be found that on gravelly and sandy soils, which have little power of holding water, organic forms of nitrogen, as rape cake and farm-yard manure, may be more certain in their effects than ammonia or nitrates. The organic manures being only slowly rendered soluble in the soil, can suffer comparatively little loss from sudden rain. The subject of the economic application of nitrogen is being further investigated at Rothamsted.

We have no space to do more than allude to the researches which have been conducted at Rothamsted in the department of animal chemistry : the experiments on the fattening of stock, and on the composition of the carcase produced, have been equally important in their results with those field experiments we have referred to. Of the indebtedness of Science to Mr. Lawes' unique and costly experiments we need not speak, the facts are so plain that they speak for themselves. Nor need we state the moral. The addition to the national wealth which has accrued from the discoveries made by Mr. Lawes is already enormous. It must be borne in mind that this benefit has arisen from accidental researches, for $\mathrm{Mr}$. Lawes was not compelled to take them up, nor is he bound to continue them. Now if such work is not national work, The Royal Observatory ought to be shut up to-morrow, for the work done there is not one jot or tittle more important.

\section{DR. LIVINGSTONE}

r $\mathrm{HE}$ telegram, dated at Aden on the 23rd of this month, announces that Lieut. Murphy is bringing the body of Dr. Livingstone down to Zanzibar, while Lieut. Cameron has passed onwards to Ujiji to recover Dr. Livingstone's papers and to continue his work. The story of those faithful negroes having carried the body of their beloved chief over hundreds of miles is one of the most romantic in history, and is a fitting close to the noble life of the great explorer. Dean Stanley, we are informed, has proposed that the remains of Livingstone shall find a last resting-place in Westminster Abbey.
Yesterday (the $25^{\text {th }}$ ) was the last day on which instructions could be sent out by telegram touching the disposal of the body. We cannot believe that the necessary orders have not been despatched; for the wishes of the country are well known, and have been sufficieritly expressed. With the body will arrive all Livingstone's faithful followers, who were engaged on the understanding that they were to receive a certain fixed monthly payment. There were Chumah and the two or three other men who had been with him since r865. There were Jacob Wainwright and the other Nassick boys, and the men sent up to Unyanyembe in the summer of 1872 ; and there were the men engaged in the interior by Dr. Livingstone himself. A sum of about r,oool. will be required to pay off these loyal and faithful servants of Her Majesty's Consul. Yesterday was the last day on which an order for the payment could be sent out. Has this been done? The people of England have a right to an answer, and an immediate answer, for if the Government hesitates, the country will never allow this disgrace to come upon it.

As soon as the full details arrive by the next mail, it will be fitting that we should give our readers a memoir of the illustrious martyr to Science who has passed away. But now we desire to know-and all England will join with us in the inquiry-whether orders were sent out by telegram on the $25^{\text {th }}$, respecting the disposal of Dr. Livingstone's body, and the payment of his followers, the devoted servants of Her Majesty's Consul?

Lieut. Cameron, in conducting the search expedition, has suffered terribly from fever and ophthalmia, and has been obliged to incur heavy expenses. But he has displayed the best qualities of an explorer. $\mathrm{He}$ is a good manager of natives, an excellent walker, an accurate astronomical observer, a linguist, and a man of indomitable perseverance. $\mathrm{He}$ is now pressing forward on a perilous and important duty, and we trust he will carry with him the generous sympathy of the Geographical Society, and of the public generally.

\section{POST-TERTIARY GEOLOGY}

The Great Ice-Age and its relation to the Antiquity of Man. By James Geikie。(W. Isbister and Co. I874.)

F VERY field-geologist, who works in northern latitudes, soon comes to know what is meant by Drift. In his attempts to trace the superposition and run across the country of the solid rocks, he is always sooner or later brought up by coming across masses of stony clay, gravel, and sand, which bury them to greater or less depths, and more or less completely hide them from view. These superficial accumulations lie indifferently on all members of the bedded formations; they occur now in detached patches, and now spread like a pall over vast tracts of country.

In the latter case it is clear that they would soon make their presence felt by the way in which they effectually mask the geological structure of the ground they cover; it was impossible, therefore, that they could be for long ignored altogether, but they seem for a time to have been looked upon as something very inferior in interest and importance to the older and more regular formations, in some 